\title{
Uso de embalagem plástica e comestível para conservação de goiaba sob diferentes condições de armazenamento
}

O Brasil está entre os dez maiores produtores mundiais de goiaba, porém também se destaca como um dos países que mais perdem ou desperdiçam alimento após a colheita, o que interfere em indicadores socioeconômicos e ambientais. No Maranhão há estimativas de até $16 \%$ de perdas pós-colheita para esta fruta cujas principais causas são desordens fisiológicas. No intuito de apresentar alternativas de baixo custo, para melhorias na conservação de goiaba 'Paluma', objetivou-se analisar a eficiência da embalagem plástica e/ou revestimento comestível, sob diferentes ambientes de armazenamento. As goiabas foram adquiridas na CEASA de São Luís (MA) e o experimento foi realizado em parcela sub-subdividida no tempo, com quatro revestimentos (saco hermético, revestimento comestível, revestimento comestível + saco hermético, sem embalagem), dois tipos de armazenamento (ambiente e refrigerado) e cinco épocas de avaliação (3, 6, 9, 12 e 15 dias). As análises consistiram em diâmetro longitudinal, perda de massa fresca, firmeza, massa de sementes, acidez total titulável e sólidos solúveis totais. Recomenda-se o uso de saco hermético para aumento da vida útil pós-colheita de goiaba 'Paluma', pois esta embalagem apresenta eficiência na manutenção de importantes atributos de qualidade, como a massa fresca, firmeza, diâmetro, acidez e teor de sólidos solúveis. O que pode reduzir perdas quantitativas, qualitativas e aumentar a aceitação comercial da fruta, mesmo em condições não refrigeradas.

\section{Use of plastic and edible packing for conservation of guava under different storage conditions}

\begin{abstract}
Brazil is among the ten largest world producers of guava, but it also stands out as one of the countries that most lose or waste food after harvest, which interferes with socioeconomic and environmental indicators. In Maranhão, there are estimates of up to $16 \%$ of post-harvest losses for this fruit, the main causes of which are physiological disorders. In order to present low-cost alternatives for improvements in the conservation of 'Paluma' guava, the objective was to analyze the efficiency of the plastic packaging and/or edible coating, under different storage environments. Guavas were purchased at CEASA in São Luís (MA) and the experiment was carried out in a sub-subdivided plot over time, with four coatings (airtight bag, edible coating, edible coating + airtight bag, without packaging), two types of storage (refrigerated) and five evaluation periods $(3,6,9,12$ and 15 days). The analyzes consisted of longitudinal diameter, loss of fresh weight firmness, seed weight, total titratable acidity and total soluble solids. The use of an airtight bag is recommended to increase the post-harvest useful life of 'Paluma' guava, as this package is efficient in maintaining important quality attributes, such as fresh mass, firmness, diameter, acidity and soluble solids content. This can reduce quantitative and qualitative losses and increase the commercial acceptance of the fruit, even in uncooled conditions.
\end{abstract}

Keywords: Psidium guajava L.; Cassava starch; Quality; Refrigeration; Airtight bag.

Topic: Planejamento, Gestão e Políticas Públicas Ambientais

Reviewed anonymously in the process of blind peer
Received: $10 / 05 / 2020$

Approved: 07/06/2020
Francisco Gilvan Borges Ferreira Freitas Júnior (1D)

Universidade Federal do Maranhão, Brasil http://lattes.cnpq.br/5174137410180479 http://orcid.org/0000-0002-8306-0310 gilvanjr582@gmail.com

Marina Pacheco Santos (D)

Universidade Federal do Maranhão, Brasil http://lattes.cnpq.br/3510423393197189 http://orcid.org/0000-0001-7516-0840 pachecos1998@gmail.com

Monik Silva de Moura (iD)

Universidade Federal do Maranhão, Brasil http.//attes cnpg br/3510423393197189 htp://orcid $0019000-0001-7516-0840$ hetp.//orcid.org//000-001-75

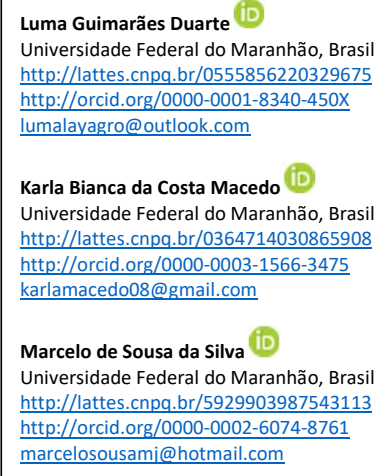

marcelosousamj@hotmail.com

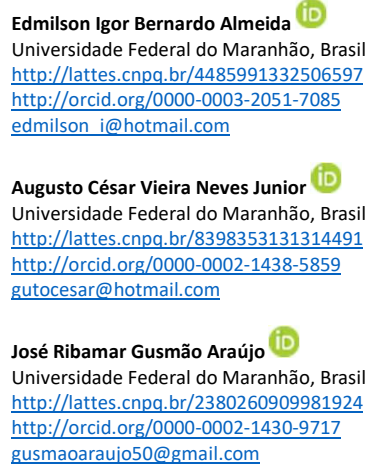

\section{Referencing this:}

FREITAS JÚNIOR, F. G. B. F.; SANTOS, M. P.; MOURA, M. S.; DUARTE, L. G.; MACEDO, K. B. C.; SILVA, M. S.; ALMEIDA, E. I. B.; NEVES JUNIOR, A. C. V.; ARAÚJO, J. R. G.; OLIVEIRA, L. B. T.. Uso de embalagem plástica e comestível para conservação de goiaba sob diferentes condições de armazenamento. Revista Ibero-Americana de Ciências Ambientais, v.11, n.4, p.463-473, 2020. DOI: http://doi.org/10.6008/CBPC2179$\underline{6858.2020 .004 .0039}$

DOI: 10.6008/CBPC2179-6858.2020.004.0039 


\section{INTRODUÇÃO}

A goiabeira (Psidium guajava L.) é uma espécie frutífera pertencente à família das Myrtaceae, cujo centro de dispersão ocorreu entre as Américas Central e do Sul. É considerada uma cultura resistente a regiões semiáridas, cultivada também em todas as regiões tropicais e subtropicais do mundo (ONIAS et al., 2018; ALENCAR et al., 2016). Segundo a Sidra em 2019 o nordeste brasileiro participou com um pouco mais de $50 \%$ da produção nacional. Pereira et al. (2011) acrescentaram que cerca de $70 \%$ das goiabeiras cultivadas atualmente, são da cultivar Paluma, o que enfatiza a necessidade de estudos sobre a mesma.

A goiaba é uma fruta climatérica, ou seja, após sua maturação fisiológica continua sofrendo transformações bioquímicas, mesmo quando desligada da planta mãe. Logo, é extremamente importante a adoção de técnicas que minimizem o seu intenso metabolismo, pois pode auxiliar na redução de perdas póscolheita, ampliação do período de conservação e comercialização de excelente qualidade para o consumo in natura (VILA et al., 2007).

Em estudos realizados no Maranhão, Ferreira et al. (2020) estimaram aproximadamente $16 \%$ de perdas pós-colheita de goiaba em sete cidades situadas na mesorregião Leste Maranhense, cujas principais causas apontadas foram as desordens fisiológicas. Todos os hortifrútis comercializados em 145 estabelecimentos eram oriundos de outros estados, como o Ceará, Piauí, Pernambuco e Bahia. O que aumenta a susceptibilidade a danos mecânicos, desordens fisiológicas e contaminações dos produtos. Nesse aspecto, alguns métodos como a refrigeração e atmosfera modificada podem ser adotados nos estabelecimentos comerciais, para melhor conservação da qualidade dos hortifrútis, aumento da rentabilidade, mitigação de perdas pós-colheita e impactos ambientais oriundos dos descartes.

A atmosfera modificada passiva consiste na utilização de embalagens plásticas ou comestíveis que originam uma barreira artificial sobre a fruta, reduzindo o seu metabolismo (OSHIRO et al., 2012; VESPUCCI et al., 2018). O que dependendo dos materiais empregados pode ser uma alternativa importante e viável para os comerciantes, pois Tomm et al. (2018) estimaram que a comercialização de hortifrútis rende apenas dois salários mínimos para a maioria dos comerciantes de seis cidades maranhenses. Fato que inviabiliza grandes investimentos no armazenamento.

As embalagens plásticas também podem apresentar boa eficiência na conservação de goiaba, a exemplo do saco hermético (PEBD e PEAD), filme plástico (PVC) e saco picotado. Landim et al. (2016) ressaltaram que embora eficientes na conservação de produtos perecíveis, esta tecnologia pode gerar resíduos ambientais após o consumo. Diferentemente dos revestimentos comestíveis que não acarretam este inconveniente e também consistem numa técnica eficiente de atmosfera passiva.

Assim, os revestimentos comestíveis têm ganhado bastante notoriedade e podem ser confeccionados a partir de proteínas, lipídeos e derivados da amilose ou celulose (OSHIRO et al., 2011). Os polissacarídeos mais utilizados na elaboração de revestimentos comestíveis, em frutas, são o amido de mandioca, alginato, pectina, carragena, quitosana e derivados da celulose (LUVIELMO et al., 2012).

Portanto, há inúmeras estratégias que podem ser adotadas para reduzir perdas pós-colheita na 
comercialização de frutas, particularmente a goiaba que segundo os estudos realizados no Maranhão, apresenta estimativas de alta magnitude. Como forma de apresentar alternativas de baixo custo, para melhorias na conservação de goiaba 'Paluma' em estabelecimentos comerciais maranhenses, objetivou-se analisar a eficiência da embalagem plástica e/ou revestimento comestível, sob diferentes ambientes de armazenamento.

\section{MATERIAIS E MÉTODOS}

O experimento foi conduzido no Laboratório de Fitotecnia e Pós-colheita (LAPOC) da Universidade Estadual do Maranhão (UEMA). Para isso, adquiriram-se goiabas 'Paluma', na Central de Abastecimento (CEASA) de São Luís (MA), em estádio de maturação 'braeker', em lote bem padronizado. Após coletadas, as frutas foram lavadas em água corrente e higienizadas com solução clorada de $150 \mathrm{mg} \cdot \mathrm{L}^{-1}$ à $12{ }^{\circ} \mathrm{C}$, por um minuto.

Uma vez sanitizados, os frutos foram secos à temperatura ambiente e acondicionados de forma aleatória nos respectivos tratamentos. Cada tratamento continha três amostras e cada amostra foi subdivida em duas parcelas, totalizando seis frutas por tratamento. $O$ experimento foi conduzido em parcela subdividida no tempo, com quatro revestimentos (saco hermético, revestimento comestível, revestimento comestível + saco hermético, sem embalagem), duas condições de armazenamento (ambiente, $25^{\circ} \mathrm{C}, 48 \%$ UR; e refrigerado, $12^{\circ} \mathrm{C}, 90 \%$ UR) e cinco épocas de avaliação $(3,6,9,12$ e 15 dias).

O saco hermético (Wyda Zip) tinha 27 × $31 \mathrm{~cm}$ de dimensão, constituído de polietileno de alta densidade (PEAD). Já a solução filmogênica foi adaptada de acordo com a metodologia de Neves Junior (2013), onde preparou-se 8 L de solução de revestimento comestível a base de fécula de mandioca. Adicionou-se primeiramente a fécula de mandioca, colocando-se aproximadamente metade do volume final de água destilada. Aqueceu-se a $70^{\circ} \mathrm{C}$ (utilizando-se banho-maria microprocessador) até formar uma liga, posteriormente diminuiu-se a fonte de calor e acrescentou-se o glicerol e o PEG 400. Com a outra metade do volume final de água, diluiu-se o permanganato de potássio antes de ser adicionado à solução.

O revestimento utilizado apresentou $3,5 \%$ de fécula de mandioca, $0,0135 \%$ de permanganato de potássio, 1\% de glicerol e 5\% de PEG 400 (em relação ao peso do polímero principal), como composição química. A fórmula original do revestimento previa uma concentração de 0,0135\% de lactato de cálcio, contudo não foi utilizado a fim de reduzir os custos.

A solução filmogênica foi preparada no dia anterior à montagem do experimento e acondicionada em geladeira. No dia seguinte, foram colocadas em baldes de $10 \mathrm{~L}$ para imersão total dos frutos, por um minuto. Após esse tempo, todas as frutas que foram submetidas ao revestimento ficaram com aproximadamente $2,48 \mathrm{ml}$ do produto, cujo cálculo para determinação da quantidade de revestimento por fruta foi feito pela seguinte fórmula:

$$
\mathrm{RF}=\frac{(\mathrm{VIS}-\mathrm{VFS})}{\mathrm{n}^{\mathrm{o}} \text { total de frutas revestidas }}
$$


$\mathrm{RF} \rightarrow$ Revestimento por fruta $(\mathrm{ml})$;

VIS $\rightarrow$ Volume Inicial da Solução (ml);

VFS $\rightarrow$ Volume Final da Solução (ml).

Após preparação da solução filmogênica, uma alíquota de $25 \mathrm{ml}$ foi vertida em placa de petri de $138,42 \times 138,36 \mathrm{~mm}$. A placa foi mantida sobre bancada nivelada por 24 horas e após esse período foi analisada a formação ou não de filme.

A cada três dias foram realizadas análises físicas e químicas em goiabas 'Paluma' submetidas a diferentes tratamentos. As análises físicas consistiram em massa de sementes (g), obtida através de balança analítica; diâmetro longitudinal $(\mathrm{mm})$, através de paquímetro digital; firmeza da polpa (kgf), por meio de penetrômetro analógico, modelo PTR-100, e medidas em dois pontos apostos no eixo equatorial da fruta; perda de massa fresca (\%), por pesagem em balança semianalítica e estimada pela seguinte fórmula:

$$
\mathrm{PM}(\%)=\frac{(\text { Massa Inicial }- \text { Massa a cada intervalo de tempo) }}{\text { Massa inicial }} \times 100
$$

*fórmula de determinação de perda de massa a cada intervalo de análise.

As análises químicas consistiram em acidez total titulável (ATT) (\% de ácido cítrico), realizada de acordo com a metodologia ISO (1998); sólidos solúveis totais (SST) ( ${ }^{\circ}$ Brix), em suco homogeneizado, através de refratômetro digital, conforme metodologia ISO (2003).

Os dados foram analisados através de análise de variância (ANOVA), pelo teste $F$, e para os casos em que a hipótese de nulidade foi rejeitada procedeu-se com a comparação de médias pelo teste Tukey, a 5\% de probabilidade. Adicionalmente foi aplicado teste multidimensional de componentes principais para avaliar os níveis de correlação entre as variáveis, massa de sementes, perda de massa fresca, ATT, SST e firmeza, as quais foram consideradas como as de maior importância para o monitoramento do amadurecimento da fruta.

\section{RESULTADOS E DISCUSSÃO}

As goiabas armazenadas em diferentes embalagens e sob diferentes temperaturas, ao longo do tempo, apresentaram interação tripla quanto à firmeza $(p=0,045)$, acidez total titulável $(p=0,001)$ e sólidos solúveis totais $(p=0,001)$. A perda de massa fresca sofreu efeito significativo da interação dupla entre as embalagens e o tempo de avaliação $(p=0,001)$, ao passo que o diâmetro transversal foi significativamente influenciado pelas embalagens e armazenamento $(p=0,03)$.

Aos 15 dias de armazenamento, verificou-se oscilação de 1,58 a 35,63\% na perda de massa fresca (Tabela 1). Apenas os resultados obtidos com o uso de saco hermético e saco hermético + revestimento comestível (fécula 3,5\%) em condições ambiente e/ou refrigerada, estão dentro dos limites recomendados por Ribeiro et al. (2005), para goiaba, cuja faixa se estende até $15 \%$.

Entretanto, é importante ressaltar que a refrigeração propiciou um expressivo efeito positivo sobre a atmosfera modificada, principalmente via saco hermético. As médias obtidas para estas condições foram 
drasticamente superiores ao uso de fécula 3,5\% isolado e ao controle. Com estimativas que apresentaram até 22,55 vezes (2.355\%) de diferença proporcional entre o melhor (saco hermético com refrigeração) e o pior tratamento (fécula 3,5\%, ambiente) para esta variável.

Tabela 1: Perda de massa (\%) goiabas 'Paluma' revestidas com fécula de mandioca e embalagem plástica, armazenadas em condições ambiente e sob refrigeração.

\begin{tabular}{|c|c|c|c|c|c|c|}
\hline \multirow[t]{2}{*}{ Embalagens } & \multirow[t]{2}{*}{ Armazenamento } & \multicolumn{5}{|c|}{ Tempo (dias) } \\
\hline & & 3 & 6 & 9 & 12 & 15 \\
\hline Controle & Ambiente & 8,75Abe & $12,60 \mathrm{ABd}$ & $19,46 \mathrm{ABCC}$ & $25,50 \mathrm{ABb}$ & $32,81 \mathrm{Aba}$ \\
\hline $\mathrm{F}_{3,5 \%}$ & Ambiente & 9,97Abe & $18,50 \mathrm{Ad}$ & $25,60 \mathrm{Ac}$ & $29,62 \mathrm{Ab}$ & $35,63 \mathrm{Aa}$ \\
\hline Saco hermético & Ambiente & $1,20 \mathrm{Ca}$ & $1,20 \mathrm{Ca}$ & $2,96 \mathrm{Ca}$ & $3,67 \mathrm{Ca}$ & $4,16 \mathrm{Ca}$ \\
\hline $\mathrm{F}_{3,5 \%}+\mathrm{SH}$ & Ambiente & $0,81 \mathrm{Ca}$ & $0,81 \mathrm{Ca}$ & $0,81 \mathrm{Ca}$ & $3,82 \mathrm{Ca}$ & $3,93 \mathrm{Ca}$ \\
\hline Controle & Refrigerado & $3,94 \mathrm{ABC} c \mathrm{~d}$ & $11,17 \mathrm{Bc}$ & $13,32 \mathrm{BC}$ & $22,48 \mathrm{Bb}$ & $27,66 \mathrm{Ba}$ \\
\hline $\mathrm{F}_{3,5 \%}$ & Refrigerado & $8,96 \mathrm{Ad}$ & $13,90 \mathrm{Abc}$ & $15,59 \mathrm{Bc}$ & $25,03 \mathrm{ABb}$ & $28,54 \mathrm{Ba}$ \\
\hline Saco hermético & Refrigerado & 0,00Ca & $0,00 \mathrm{Ca}$ & 0,00Ca & $1,58 \mathrm{Ca}$ & $1,58 \mathrm{Ca}$ \\
\hline \multirow[t]{2}{*}{$\mathrm{F}_{3,5 \%}+\mathrm{SH}$} & Refrigerado & $2,04 \mathrm{Ca}$ & $2,70 \mathrm{Ca}$ & $2,69 \mathrm{Ca}$ & $2,69 \mathrm{Ca}$ & $4,08 \mathrm{Ca}$ \\
\hline & & $\mathrm{P}$ & CV\% & & & \\
\hline \multicolumn{2}{|l|}{ Embalagens } & $<0,001 * *$ & 20,00 & & & \\
\hline \multicolumn{2}{|l|}{ Armazenamento } & 0,058 & & & & \\
\hline \multicolumn{2}{|c|}{ Embalagens $\mathrm{x}$ armazenamento } & 0,39 & & & & \\
\hline \multicolumn{2}{|l|}{ Tempo } & $<0,001 * *$ & & & & \\
\hline \multicolumn{2}{|c|}{ Tempo x embalagens } & $<0,001^{* *}$ & & & & \\
\hline \multicolumn{2}{|c|}{ Tempo $\mathrm{x}$ armazenamento } & 0,07 & & & & \\
\hline \multicolumn{2}{|c|}{ Embalagens $x$ Tempo x Armaz } & 0,41 & & & & \\
\hline
\end{tabular}

Fécula de Mandioca (3,5\%): F3,5\%; Saco Hermético: SH; Armazenamento: Armaz; Coeficiente de Variação: CV. * Significativo a $5 \%$ de probabilidade pelo teste Tukey. ${ }^{*}$ Significativo a $1 \%$ de probabilidade pelo teste Tukey. Médias seguidas de letras maiúsculas iguais na mesma coluna e letras minúsculas iguais na mesma linha, não diferiram estatisticamente entre si.

A fécula 3,5\% não apresentou eficiência quando utilizado isoladamente, pois a perda de massa foi de 35,63 e $28,54 \%$, sob condições ambiente e refrigerada, respectivamente. As quais não diferiram estatisticamente do controle (Tabela 1). O que possivelmente deve-se a porosidade do revestimento comestível.

Isso corrobora com Oliveira et al. (2011), os quais utilizaram revestimentos a base de gelatina e reportaram que estes permitiram a livre permeação de vapor d'água e trocas gasosas entre a fruta (tomate) e o ambiente. Nunes et al. (2004) ao testarem o revestimento a base de fécula de mandioca 3\%, obtiveram perdas de massa superiores à testemunha (não embalada).

Em consonância a isto, a complementação do revestimento comestível com saco hermético pode ter aumentado a barreira artificial sobre a fruta e consequentemente reduzido a perda de água e atividade metabólica, o que culminou em redução na perda de massa fresca (Tabela 1). De acordo com Santos et al. (2008), a embalagem plástica pode atuar com uma barreira protetora mais eficaz na conservação da goiaba, embora possa ocasionar inconvenientes ambientais resultantes do descarte após o consumo.

A firmeza variou de 1,21 a 8,80 kgf (Tabela 2). Aos 15 dias de avaliação, verificaram-se maiores médias em frutas embaladas com saco hermético associado à fécula 3,5\%, em condições ambiente e refrigerada, o que pode indicar maior retardamento no amadurecimento da goiaba. Esses resultados ajustam-se aos obtidos para perda de massa fresca e indicam que frutas com maior firmeza apresentam menor perda de massa (Tabela 1 e 2). 
Tabela 2: Firmeza (kgf) de goiabas 'Paluma' revestidas com fécula de mandioca e embalagem plástica, armazenadas em condições ambiente e sob refrigeração.

\begin{tabular}{|c|c|c|c|c|c|c|}
\hline \multirow[t]{2}{*}{ Embalagens } & \multirow[t]{2}{*}{ Armazenamento } & \multicolumn{5}{|c|}{ Tempo (dias) } \\
\hline & & 3 & 6 & 9 & 12 & 15 \\
\hline Controle & Ambiente & $4,71 \mathrm{Ba}$ & 3,81Cab & $1,80 \mathrm{Dc}$ & $3,60 \mathrm{Bb}$ & $3,03 \mathrm{Bbc}$ \\
\hline $\mathrm{F}_{3,5 \%}$ & Ambiente & 4,91Ba & $4,68 \mathrm{BCa}$ & $2,96 \mathrm{CDb}$ & $3,43 \mathrm{Bab}$ & $3,60 \mathrm{ABab}$ \\
\hline Saco hermético & Ambiente & $3,96 \mathrm{Ba}$ & $5,06 \mathrm{BCa}$ & 3,51BCa & $3,75 \mathrm{Ba}$ & 4,76Aa \\
\hline $\mathrm{F}_{3,5 \%}+\mathrm{SH}$ & Ambiente & $4,61 \mathrm{Ba}$ & $3,53 \mathrm{Ca}$ & $4,16 \mathrm{BCa}$ & $3,53 \mathrm{Ba}$ & $4,71 \mathrm{Aa}$ \\
\hline Controle & Refrigerado & $8,80 \mathrm{Aa}$ & $6,20 \mathrm{ABb}$ & $4,20 \mathrm{BCd}$ & $5,43 \mathrm{Abc}$ & $3,31 \mathrm{ABd}$ \\
\hline $\mathrm{F}_{3,5 \%}$ & Refrigerado & 7,71Aa & $7,28 \mathrm{Aa}$ & $6,20 \mathrm{Aa}$ & $4,38 \mathrm{ABb}$ & $4,33 \mathrm{ABb}$ \\
\hline Saco hermético & Refrigerado & $1,21 \mathrm{Cc}$ & $5,25 \mathrm{BCa}$ & 4,33BCab & $3,45 \mathrm{Bb}$ & $4,08 \mathrm{ABab}$ \\
\hline \multirow[t]{2}{*}{$\mathrm{F}_{3,5 \%}+\mathrm{SH}$} & Refrigerado & $4,78 \mathrm{Ba}$ & $4,76 \mathrm{BCa}$ & 4,96ABa & $3,60 \mathrm{Ba}$ & $4,05 \mathrm{Aba}$ \\
\hline & & $\mathrm{P}$ & CV\% & & & \\
\hline \multicolumn{2}{|l|}{ Embalagens } & $0,005^{*}$ & 2,25 & & & \\
\hline \multicolumn{2}{|l|}{ Armazenamento } & $<0,001 * *$ & & & & \\
\hline \multicolumn{2}{|c|}{ Embalagens $x$ armaz } & $<0,001^{* *}$ & & & & \\
\hline \multicolumn{2}{|l|}{ Tempo } & $<0,001 * *$ & & & & \\
\hline \multicolumn{2}{|c|}{ Tempo $\mathrm{x}$ embalagens } & $<0,001 * *$ & & & & \\
\hline \multicolumn{2}{|l|}{ Tempo x Armaz } & $0,014 *$ & & & & \\
\hline \multicolumn{2}{|c|}{ Embalagens $\times$ Tempo $\times$ Armaz } & $0,045^{*}$ & & & & \\
\hline
\end{tabular}

Fécula de Mandioca (3,5\%): $\mathrm{F}_{3,5 \%}$; Saco Hermético: SH; Armazenamento: Armaz; Coeficiente de Variação: CV. * Significativo a $5 \%$ de probabilidade pelo teste Tukey. ${ }^{* *}$ Significativo a $1 \%$ de probabilidade pelo teste Tukey. Médias seguidas de letras maiúsculas iguais na mesma coluna e letras minúsculas iguais na mesma linha, não diferiram estatisticamente entre si.

Neste aspecto, Grigio et al. (2011) ressaltaram que a goiaba apresenta em torno de $74 \%$ de água em sua composição química e com isso, a perda de massa fresca pode induzir a redução de firmeza. Logo, há maior susceptibilidade a danos mecânicos, pela solubilização das pectinas presentes na parede celular. Os autores salientaram que o limite mínimo aceitável de firmeza para transporte e consumo é de 2,0 kgf. Assim, aos 15 dias de armazenamento todos os tratamentos proporcionaram condições mínimas para o transporte e consumo da goiaba, todavia com drásticas variações.

Onias et al. (2018) acrescentaram que a firmeza é um dos principais atributos de qualidade julgados pelo consumidor e, portanto, é extremamente importante na aceitação geral do produto. Em vista disso, entende-se que a utilização de saco hermético com revestimento comestível, em condição refrigerada ou não, pode ser uma importante alternativa para controle da qualidade da goiaba e sua conseguinte intenção de compra.

Tabela 3: Diâmetro longitudinal $(\mathrm{mm})$ de goiabas 'Paluma' revestidas com fécula de mandioca e embalagem plástica, armazenadas em condições ambiente e sob refrigeração.

\begin{tabular}{|c|c|c|c|}
\hline \multirow{2}{*}{ Embalagens } & \multicolumn{3}{|c|}{ Armazenamento } \\
\hline & Ambiente & Refrigerado & Média \\
\hline Controle & $59,5 \mathrm{Ba}$ & $56,8 \mathrm{Ba}$ & $58,2 \mathrm{C}$ \\
\hline$F_{3,5 \%}$ & $59,6 \mathrm{Bb}$ & $66,3 \mathrm{Aa}$ & $63,3 B$ \\
\hline Saco hermético & $61,2 \mathrm{Ba}$ & $63,6 \mathrm{Aa}$ & $63,2 B$ \\
\hline $\mathrm{F}_{3,5 \%}+\mathrm{SH}$ & $66,8 \mathrm{Aa}$ & $66,3 \mathrm{Aa}$ & $66,6 \underline{a}$ \\
\hline \multirow[t]{2}{*}{ Média } & $61,2^{a}$ & $63,2 a$ & \\
\hline & $\mathrm{P}$ & CV (\%) & \\
\hline Embalagens & $<0,001^{* *}$ & 6,64 & \\
\hline Armazenamento & 0,21 & & \\
\hline Embalagens $x$ Armaz & $0,03 *$ & & \\
\hline Tempo & 0,23 & & \\
\hline Tempo x Embalagens & 0,49 & & \\
\hline Tempo x Armaz & 0,20 & & \\
\hline Embalagens $\times$ Tempo $\times$ Armaz & 0,40 & & \\
\hline
\end{tabular}


Significativo a $5 \%$ de probabilidade pelo teste Tukey. ${ }^{* *}$ Significativo a $1 \%$ de probabilidade pelo teste Tukey. Médias seguidas de letras maiúsculas iguais na mesma coluna e letras minúsculas iguais na mesma linha, não diferiram estatisticamente entre si.

O diâmetro longitudinal variou entre 56,8 e $66,8 \mathrm{~mm}$ (Tabela 3). Segundo Silva et al. (2019), o diâmetro é uma característica física que sofre pouca influência do tempo de prateleira. Contudo, foi possível observar que houve uma significativa redução do diâmetro longitudinal médio, em frutos não embalados, notadamente em condições ambiente. Ao passo que, a adoção de saco hermético em conjunto com a fécula de mandioca 3,5\% apresentou a melhor média (Tabela 3).

Em condições de refrigeração, apenas o controle diferiu significativamente e corrobora a importância desta técnica para melhorias na conservação da goiaba, em vários atributos de qualidade (Tabela 3). Pois, é provável que a redução do diâmetro longitudinal esteja relacionada à perda de massa fresca e firmeza da fruta (Tabela 1, 2 e 3). No que diz respeito às variáveis químicas, verificou-se que o teor de sólidos solúveis totais (SST) variou de 4,35 a 15,14 ํBrix (Tabela 4). Aos 15 dias de armazenamento, o saco hermético em condições ambiente diferiu significativamente dos demais tratamentos, como a menor média.

Tabela 4: Sólidos Solúveis Totais (SST - oBrix) de goiabas 'Paluma' revestidas com fécula de mandioca e embalagem plástica, armazenadas em condições ambiente e sob refrigeração.

\begin{tabular}{|c|c|c|c|c|c|c|}
\hline \multirow[t]{2}{*}{ Embalagens } & \multirow[t]{2}{*}{ Armazenamento } & \multicolumn{5}{|c|}{ Tempo (dias) } \\
\hline & & 3 & 6 & 9 & 12 & 15 \\
\hline Controle & Ambiente & $8,89 \mathrm{Aba}$ & 9,17Aa & $9,40 \mathrm{Aa}$ & $9,92 \mathrm{Ba}$ & $8,14 \mathrm{Ca}$ \\
\hline $\mathrm{F}_{3,5 \%}$ & Ambiente & $9,20 \mathrm{Aba}$ & 7,44BCab & 8,49Aab & $8,62 \mathrm{BCab}$ & $7,20 \mathrm{CDb}$ \\
\hline Saco hermético & Ambiente & $8,74 \mathrm{ABCa}$ & $5,65 \mathrm{Cbc}$ & $6,46 \mathrm{Cb}$ & 5,98DEbc & $4,35 \mathrm{Ec}$ \\
\hline $\mathrm{F}_{3,5 \%}+\mathrm{SH}$ & Ambiente & 7,11Ca & $7,48 \mathrm{Ba}$ & 7,07BCa & $4,46 \mathrm{~Eb}$ & $6,25 \mathrm{Da}$ \\
\hline Controle & Refrigerado & $9,72 A b$ & $9,17 \mathrm{ABb}$ & $9,79 A b$ & $14,44 \mathrm{Aa}$ & $15,14 \mathrm{Aa}$ \\
\hline $\mathrm{F}_{3,5 \%}$ & Refrigerado & $6,26 \mathrm{BCcD}$ & $8,85 \mathrm{ABb}$ & $9,71 \mathrm{Ab}$ & $8,70 \mathrm{BCb}$ & $12,56 \mathrm{Ba}$ \\
\hline Saco hermético & Refrigerado & $7,45 \mathrm{CBa}$ & $7,70 \mathrm{Ba}$ & 7,41BCa & $5,83 \mathrm{DEa}$ & $7,68 \mathrm{CDa}$ \\
\hline \multirow[t]{2}{*}{$\mathrm{F}_{3,5 \%}+\mathrm{SH}$} & Refrigerado & $5,30 \mathrm{Db}$ & $7,50 \mathrm{Ba}$ & $8,20 \mathrm{ABCa}$ & 6,96DCab & $7,27 \mathrm{CDa}$ \\
\hline & & $\mathrm{P}$ & CV\% & & & \\
\hline \multicolumn{2}{|l|}{ Embalagens } & $<0,001^{* *}$ & 2,83 & & & \\
\hline \multicolumn{2}{|l|}{ Armazenamento } & $<0,001^{* *}$ & & & & \\
\hline \multicolumn{2}{|c|}{ Embalagens $\mathrm{x}$ armazenamento } & $0,005^{*}$ & & & & \\
\hline \multicolumn{2}{|c|}{ Tempo } & 0,19 & & & & \\
\hline \multicolumn{2}{|c|}{ Tempo x Embalagens } & $<0,001^{* *}$ & & & & \\
\hline \multicolumn{2}{|c|}{ Tempo x Armazenamento } & $<0,001^{* *}$ & & & & \\
\hline \multicolumn{2}{|c|}{ Embalagens $\times$ Tempo $\times$ Armaz } & $<0,001^{* *}$ & & & & \\
\hline
\end{tabular}

Fécula de Mandioca (3,5\%): F3,5\%; Saco Hermético: SH; Armazenamento: Armaz; Coeficiente de Variação: CV. * Significativo a $5 \%$ de probabilidade pelo teste Tukey. ${ }^{* *}$ Significativo a $1 \%$ de probabilidade pelo teste Tukey. Médias seguidas de letras maiúsculas iguais na mesma coluna e letras minúsculas iguais na mesma linha, não diferiram estatisticamente entre si.

Isto sugere que este tratamento diminuiu eficientemente o metabolismo da fruta, com retardamento na síntese de açúcares solúveis, que tem seu pico no ponto de amadurecimento, conforme ressaltado por Chitarra et al. (2005). Esses autores enfatizaram que estes açúcares são oriundos de processos biossintéticos ou da deterioração de polissacarídeos, e são importantes indicadores de colheita e armazenamento.

A acidez total titulável variou entre 0,60 e 1,45\% (Tabela 5). Segundo Oniais et al. (2018), o ácido orgânico predominante nas goiabas é o cítrico, o qual durante os processos metabólicos do amadurecimento é convertido em moléculas não ácidas, reduzindo a acidez da polpa. O que geralmente apresenta relação inversamente proporcional com os sólidos solúveis totais nas transições da maturação. 
Tabela 5: Acidez Total Titulável (ATT) de goiabas 'Paluma' revestidas com fécula de mandioca e embalagem plástica, armazenadas em condições ambiente e sob refrigeração.

\begin{tabular}{|c|c|c|c|c|c|c|}
\hline \multirow[t]{2}{*}{ Embalagens } & \multirow[t]{2}{*}{ Armazenamento } & \multicolumn{5}{|c|}{ Tempo (dias) } \\
\hline & & 3 & 6 & 9 & 12 & 15 \\
\hline Controle & Ambiente & $0,88 \mathrm{ABb}$ & 0,97Aab & $1,10 \mathrm{Aa}$ & $1,14 \mathrm{Ba}$ & $1,05 \mathrm{Ba}$ \\
\hline $\mathrm{F}_{3,5 \%}$ & Ambiente & $0,85 \mathrm{BC}$ & 0,99Aabc & $0,90 \mathrm{BCbc}$ & $1,06 \mathrm{Bcab}$ & $1,10 \mathrm{Ba}$ \\
\hline Saco hermético & Ambiente & $0,80 \mathrm{Ba}$ & 0,79Bа & $0,80 \mathrm{Ca}$ & $0,87 \mathrm{Ca}$ & $0,67 \mathrm{Da}$ \\
\hline $\mathrm{F}_{3,5 \%}+\mathrm{SH}$ & Ambiente & $0,79 \mathrm{Ba}$ & $0,88 \mathrm{Aba}$ & $0,83 \mathrm{Ca}$ & $0,67 \mathrm{Db}$ & $0,77 \mathrm{Ca}$ \\
\hline Controle & Refrigerado & $0,92 \mathrm{Ab}$ & $0,96 \mathrm{ABb}$ & $0,96 \mathrm{ABCb}$ & $1,45 \mathrm{Aa}$ & $1,29 \mathrm{Aa}$ \\
\hline $\mathrm{F}_{3,5 \%}$ & Refrigerado & $0,81 \mathrm{BC}$ & $0,88 \mathrm{ABbc}$ & $1,01 \mathrm{ABb}$ & $0,96 \mathrm{Cbc}$ & $1,43 \mathrm{Aa}$ \\
\hline Saco hermético & Refrigerado & $0,82 \mathrm{Aba}$ & $0,75 B a b c$ & 0,81Cab & $0,60 \mathrm{Dc}$ & $0,88 \mathrm{Ca}$ \\
\hline \multirow[t]{2}{*}{$\mathrm{F}_{3,5 \%}+\mathrm{SH}$} & Refrigerado & $0,82 \mathrm{Ba}$ & $0,76 \mathrm{Ba}$ & $0,86 \mathrm{BCa}$ & $0,89 \mathrm{Ca}$ & $0,86 \mathrm{Ca}$ \\
\hline & & $\mathrm{P}$ & V\% & & & \\
\hline \multicolumn{2}{|l|}{ Embalagens } & $<0,001^{* *}$ & 11,29 & & & \\
\hline \multicolumn{2}{|l|}{ Armazenamento } & $0,007^{*}$ & & & & \\
\hline \multicolumn{2}{|c|}{ Embalagens $\mathrm{x}$ armazenamento } & 0,19 & & & & \\
\hline \multicolumn{2}{|l|}{ Tempo } & $<0,001 * *$ & & & & \\
\hline \multicolumn{2}{|c|}{ Tempo $x$ embalagens } & $<0,001 * *$ & & & & \\
\hline \multicolumn{2}{|c|}{ Tempo $\mathrm{x}$ armazenamento } & $0,002^{*}$ & & & & \\
\hline \multicolumn{2}{|c|}{ Embalagens $x$ Tempo $\times$ Armaz } & $<0,001 * *$ & & & & \\
\hline
\end{tabular}

Fécula de Mandioca (3,5\%): $\mathrm{F}_{3,5 \%}$; Saco Hermético: SH; Armazenamento: Armaz; Coeficiente de Variação: CV. * Significativo a $5 \%$ de probabilidade pelo teste Tukey. ${ }^{* *}$ Significativo a $1 \%$ de probabilidade pelo teste Tukey. Médias seguidas de letras maiúsculas iguais na mesma coluna e letras minúsculas iguais na mesma linha, não diferiram estatisticamente entre si.

Logo, entende-se que as técnicas de conservação menos eficientes devem, geralmente, apresentar menor teor de acidez total titulável e maior teor de SST. Contudo, no presente estudo, os tratamentos mais eficazes para conservação de atributos de qualidade da fruta, como a massa fresca, firmeza, diâmetro longitudinal e sólidos solúveis totais, apresentaram-se como os de menor ATT. Isso pode ser explicado com base em Berci et al. (2019) e Cerqueira et al. (2011).

Segundo esses autores, no início do amadurecimento da goiaba há aumento no teor ácido ascórbico, o que propicia aumento expressivo da acidez até o ponto de consumo. Desse modo, as menores médias de ATT, obtidas com o uso de saco hermético e fécula de mandioca 3,5\% associada ao saco hermético (Tabela 5), em condições ambiente e/ou refrigeradas, embasam um retardamento no amadurecimento da goiaba até os 15 dias de avaliação. Outra hipótese seria que quando os frutos perdem massa e consequentemente água, tanto os açúcares quanto os ácidos não degradados ficam mais concentrados na polpa, conforme ressaltado por Pinto et al. (2012).

A análise dos componentes principais da correlação entre as variáveis, massa de sementes, firmeza, perda de massa, ATT e SST estão apresentadas na Figura 1. O componente 1 explicou 63,79\% da variância total e o componente $2,17,43 \%$. No eixo 1 observa-se que as variáveis SST, ATT e perda de massa, que são intrínsecas ao amadurecimento, atingiram valores maiores que 0,7 , indicando uma forte correlação entre si. A firmeza por sua vez apresentou uma moderada correlação no eixo $1(0,68)$, porém uma forte correlação no eixo 2 com as varáveis citadas (SST, ATT e perda de massa).

Segundo Grigio et al. (2011), as pectinas estão relacionadas a resistência dos tecidos que compõe o fruto. Em decorrência do amadurecimento, à medida que estas pectinas são solubilizadas, o fruto perde firmeza e massa fresca, potencializados pelas trocas gasosas. A massa de semente atingiu valor abaixo de 0,5 no segundo eixo (Figura 1), o que indica fraca correlação com as demais variáveis. Segundo Jorge et al. (2018), 
a transferência de massa seca da planta para as sementes, finda no momento em que estas atingem a maturidade fisiológica. Porém em algumas espécies, essa maturidade pode ocorrer após a colheita com as sementes ainda no fruto. Como observado na Figura 1, a massa de semente possivelmente atingiu seu ponto de maturação fisiológica antes da colheita, já que obteve uma forte correlação inversamente proporcional no primeiro eixo com as variáveis atribuídas ao amadurecimento após a colheita.

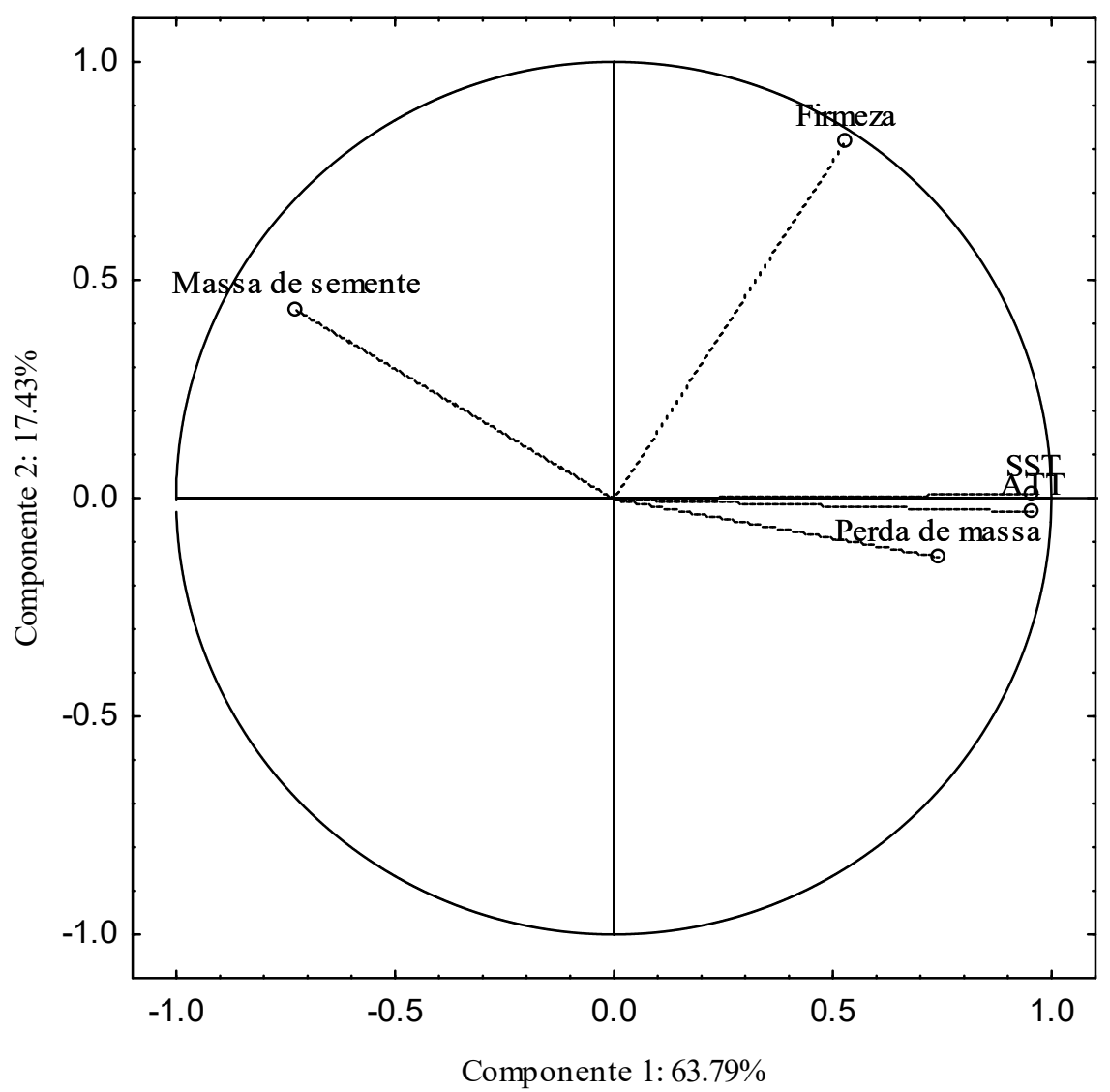

ATT: acidez titulável total, SST: sólidos solúveis totais. Autovalores acumulados: 81,22.

Figura 1: Análise da correlação entre massa de sementes, firmeza, perda de massa, ATT e SST de goiaba 'Paluma', em aspectos de componentes principais.

De modo geral, os melhores resultados para manutenção da qualidade e aumento do tempo de prateleira da goiaba 'Paluma' foram obtidos com a adoção de saco hermético e saco hermético + revestimento comestível (fécula 3,5\%), em condições ambiente e/ou refrigerada. Considerados os aspectos de inserção destas tecnologias em estabelecimentos comerciais maranhenses ou de condições de rentabilidade semelhantes, recomenda-se a refrigeração como facultativa, tendo em vista ser uma tecnologia com alto custo de implantação e manutenção.

Quanto aos tópicos ambientais, a adoção do revestimento comestível seria uma importante estratégia na redução de resíduos, principalmente após o consumo. Entretanto, a fécula 3,5\% apresentou-se ineficiente na ausência da embalagem plástica (saco hermético), possivelmente devido à porosidade. Assim, novos estudos com outra matéria-prima, concentrações e formulações podem apresentar alternativas mais eficazes nos contextos fisiológicos, financeiros e ambientais. Embora, compreenda-se que o fato de se reduzirem perdas pós-colheita, já será um grande passo. 


\section{CONCLUSÕES}

O uso de atmosfera modificada passiva, através de saco hermético e saco hermético em conjunto com revestimento comestível (fécula de mandioca 3,5\%), sob condições ambiente $\left(25^{\circ} \mathrm{C}, 48 \% \mathrm{UR}\right.$ ) e/ou refrigerada $\left(12^{\circ} \mathrm{C}, 90 \%\right.$ UR), pode ser recomendado como uma eficiente alternativa para a conservação de importantes atributos de qualidade da goiaba 'Paluma', como a massa fresca, firmeza e sólidos solúveis. O que pode reduzir perdas quantitativas e/ou qualitativas com consequentes impactos nos indicadores socioeconômicos e ambientais.

AGRADECIMENTOS: À Fundação de Amparo à Pesquisa e ao Desenvolvimento Científico e Tecnológico no Estado do Maranhão pelo auxílio financeiro concedido no Edital Universal 31/2016, processo 960/17.

\section{REFERÊNCIAS}

ALENCAR, R. D.; LEITE, G. A.; MENDONÇA, V.; LIMA, F. V.; PEREIRA, G. A.; FARIAS, W. C.. Adubação potássica na produção e qualidade pós-colheita de goiaba 'Paluma' no semiárido potiguar. Comunicata Scientiae, v.7, n.1, p.139148, 2016. DOI: http://doi.org/10.14295/CS.v7i1.1332

BERCI, G.; OLIVEIRA, S.; LIMA, A. P. C.; MOREIRA, W. M. Q. Perdas pós-colheita na cultura da goiabeira. Science and Technology Innovation in Agronomy, v.3, p.134-151, 2019.

CERQUEIRA, T. S.; JACOMINO, A. P.; SASAKI, F. F.; ALLEONI, A. C. C.. Recobrimento de goiabas com filmes proteicos e de quitosana. Bragantia, Campinas, v.70, p.216-221, 2011. DOI: https://doi.org/10.1590/S0006-87052011000100028

CHITARRA, M. I. F.; CHITARRA, A.. Post-harvest of fruits and vegetables: Physiology and handling. Lavras: UFLA, 2005.

FERREIRA, A. G. C.; FERREIRA, L. S.; FREITAS JÚNIOR, F. G. B. F.; SANTOS, M. P.; SILVA, M. S.; AGUIAR, F. I. S.; COSTA, T. V.; ALMEIDA, E. I. B.; SOUSA, W. S.; FREITAS, J. R. B.. Postharvest Losses of Fruits and Vegetables Marketed in Seven Municipalities of the East Mesorregion, Maranhão, Brazil. Journal of Agricultural Studies, v.8, n.3, p.335-351, 2020. DOI: https://doi.org/10.5296/jas.v8i3.16098

GRIGIO, M. L.; NEVES, L. C.; TOSIN, J. M.; NASCIMENTO, C. R.; CHAGAS, E. A; VIEITES, R. L.. Efeito da modificação atmosférica em goiabas var. Paluma na redução de danos mecânicos em pós colheita. Revista Agro@mbiente, v.5, p.57-65, 2011.

ISO. International Organization for Standardization. ISO n.750: Fruit and vegetable products: Determination of titratable acidity. Geneva: ISO, 1998.

ISO. International Organization for Standardization. ISO n.2173: Fruit and vegetable products: Determination of soluble solids, Refractometric method. Geneva: ISO, 2003.

JORGE, E. V. C.; DAVID, A. M. S. S.; FIGUEIREDO, J. C.; BERNARDINO, D. L. M. P.; SILVA, R. A. N.; ALVES, R. A.. Estádio de maturação e repouso pós-colheita dos frutos na qualidade de sementes de pimenta biquinho. Revista de Ciências Agrárias Amazonian Journal of Agricultural and Environmental Sciences, v.61, n.1, p.1-7, 2011. DOI: http://dx.doi.org/10.22491/rca.2018.2725

LANDIM, A. P. M.; BERNARDO, C. O.; MARTINS, I. B. A.; FRANCISCO, M. R.; SANTOS, M. B.; MELO, N. R..

Sustentabilidade quanto às embalagens de alimentos no Brasil. Polímeros: Ciência e Tecnologia, v.26, n.1, p.82-92, 2016. DOI: https://doi.org/10.1590/0104-1428.1897

LUVIELMO, M. M.; LAMAS, S. V.. Revestimentos comestíveis em frutas. Estudos Tecnológicos em Engenharia, v.8, n.1, p.8-15, 2012. DOI: http://doi.org/10.4013/ete.2012.81.02

NEVES JUNIOR, A. C. V.; CONEGLIAN, R. C. C.; SOARES, A. G.; FREITAS, D. G. C.; FONSECA, M. J. O.; BARBOZA, H. T. G. Evaluation Of Refrigerated Storage Of 'Mikado' Fresh Persimmon Using Edible Coatings. Acta Horticulturae, v.1012, n.1, p.1517-1522, 2013. DOI: http://doi.org/10.17660/ActaHortic.2013.1012.206

NUNES, E. E.; BOAS, B. M. V.; CARVALHO, G. L.; SIQUEIRA, H. H.; LIMA, L. C. O.. Vida útil de pêssegos 'Aurora' armazenados sob atmosfera modificada e refrigeração. Revista Brasileira de Fruticultura, v.26, n.3, p.438-440, 2004. DOI: https://doi.org/10.1590/S010029452004000300016

OLIVEIRA, T. A.; LEITE, R. H. L.; AROUCHA, E. M. M.; FERREIRA, R. M. A.. Efeito do revestimento de tomate com biofilme na aparência e perda de massa durante o armazenamento. Revista Verde de Agroecologia e Desenvolvimento Sustentável, v.6, n.1, p.230-234, 2011.

ONIAS, E. A.; TEODOSIO, A. E. M. M.; BOMFIM, M. P.; ROCHA, R. H. C.; LIMA, J. F.; MEDEIROS, M. L. S.. Revestimento biodegradável à base de Spirulina platensis na conservação pós-colheita de goiaba Paluma mantidas sob diferentes temperaturas de armazenamento. Revista de Ciências Agrárias, v.41, n.3, p.849-860, 2018. DOI: http://dx.doi.org/10.19084/RCA17201 
OSHIRO, A. M.; DRESCH, D. M.; SCALON, S. P. Q.. Preservação de goiabas 'Pedro Sato' armazenadas sob atmosfera modificada em refrigeração. Revista de Ciências Agrárias, v.35, n.1, p.213-221, 2012.

OSHIRO, A. M.; SCALON, S. P. Q.; ARGANDOÑA, E. J. S.; ZÁRATE, N. A. H.. Conservação pós-colheita de goiabas 'Pedro Sato' em atmosfera modificada, associada ou não à refrigeração. Revista Agrarian, Dourados, v.4, n.14, p.294302, 2011. DOI:

http://doi.org/10.30612/agrarian.v4i14.1245

PEREIRA, F. M.; KAVATI, R.. Contribuição da pesquisa científica brasileira no desenvolvimento de algumas frutíferas de clima subtropical. Revista Brasileira de Fruticultura, Jabotical, v.33, n.1, p.92-108, 2011. DOI: https://doi.org/10.1590/S0100-29452011000500013

PINTO, J. A. V.; BRACKMANN, A.; SCHORR, M. R. W.; VENTURINI, T. L.; THEWES, F. R.. Indução de perda de massa na qualidade pós-colheita de pêssegos' Eragil' em armazenamento refrigerado. Ciência Rural, v.42, n.6, p.962968, 2012. DOI: https://doi.org/10.1590/S0103$\underline{84782012000600002}$

RIBEIRO, V. G.; ASSIS, J. G. SILVA, J. J.; SIQUEIRA, P. P. X.; VILARONGA, C. C. P.. Armazenamento de goiabas 'Paluma' sob refrigeração e em condição ambiente, com e sem tratamento com cera de carnaúba. Revista Brasileira de Fruticultura, Jaboticabal, v.27, n.2, p.203-206, 2005. DOI: http://doi.org/10.1590/S0100-29452005000200005
SANTOS, C. A. A.; CASTRO, J. V.; PICOLI, A. A.; ROLIM, G. S. Uso de quitosana e embalagem plástica na conservação póscolheita de pêssegos' Douradão'. Revista Brasileira de Fruticultura, Jaboticabal, v.30, n.1, p.88-93, 2008. DOI: https://doi.org/10.1590/S0100-29452008000100017

SILVA, V. P.; PAZ, M. A.; SOUSA, K. S. M.; ABREU, A. K. F.. Qualidade pós-colheita de frutos de umbuzeiro (Spondias tuberosa Arr.) embalados com filme de PVC. Revista Craibeiras de Agroecologia, v.4, n.1, p.e7714, 2019.

TOMM, T. F. R.; ALMEIDA, E. I. B.; FIGUEIRINHA, K. T.; FERREIRA, L. S.; AMORIM, D. J.; GONDIM, M. M. S.. Origin and post-harvest losses of vegetables in the microregion of Chapadinha, Maranhão, Brazil. Revista Agro@mbiente, v.12, n.3, p.200-212, 2018. DOI: http://dx.doi.org/10.18227/19828470ragro.v12i3.5026

VESPUCCI, I. L.; SILVA, D. D. A.; MACHADO, V. S.; CAMPOS, A. J.. Conservação de maracujá silvestre sob atmosfera modificada passiva. Revista Eletrônica de Educação da Faculdade Araguaia, v.13, n.3, p.32-43, 2018.

VILA, M. T. R.; LIMA, L. C. O.; BOAS, E. V. B. V.; HOJO, E. T. D.; RODRIGUES, L. J.; PAULA, N. R. F.. Caracterização química e bioquímica de goiabas armazenadas sob refrigeração e atmosfera modificada. Ciência e Agrotecnologia, Lavras, v.31, n.5, p.1435-1442, 2007. DOI: $10.1590 /$ S1413$\underline{70542007000500025}$

A CBPC - Companhia Brasileira de Produção Científica (CNPJ: 11.221.422/0001-03) detém os direitos materiais desta publicação. Os direitos referem-se à publicação do trabalho em qualquer parte do mundo, incluindo os direitos às renovações, expansões e disseminações da contribuição, bem como outros direitos subsidiários. Todos os trabalhos publicados eletronicamente poderão posteriormente ser publicados em coletâneas impressas sob coordenação da Sustenere Publishing, da Companhia Brasileira de Produção Científica e seus parceiros autorizados. Os (as) autores (as) preservam os direitos autorais, mas não têm permissão para a publicação da contribuição em outro meio, impresso ou digital, em português ou em tradução. 